\title{
Effects of Synbiotics on Inflammatory Markers in Patients With Type 2 Diabetes Mellitus
}

\author{
Akram Kooshki A. ${ }^{1}$, Tahereh Tofighiyan ${ }^{2} \&$ Mohamad Hassan Rakhshani ${ }^{3}$ \\ ${ }^{1}$ School of Medicine, Sabzevar University of Medical Sciences, Sabzevar, Iran \\ ${ }^{2}$ School of Nursing, Sabzevar University of Medical Sciences, Sabzevar, Iran \\ ${ }^{3}$ School of Health Sciences, Sabzevar University of Medical Sciences, Sabzevar, Iran \\ Correspondence: Tahereh Tofighiyan, School of Nursing, Sabzevar University of Medical Sciences,Sabzevar, \\ Iran. E-mail: tofighiyan260@gmail.com
}

Received: December 2, 2014 Accepted: January 28, 2015 Online Published: March 26, 2015

doi:10.5539/gjhs.v7n7p1 URL: http://dx.doi.org/10.5539/gjhs.v7n7p1

\begin{abstract}
Introduction: With regard to the relationship between inflammation and insulin resistance and due to the lack of researches conducted about the effect of synbiotics on inflammatory markers in diabetes patients, this study was designed to investigate the effect of these markers.

Methods: A double-blind, placebo-controlled trial was conducted among 44 type 2 diabetes patients. They were randomized to symbiotic or placebo group. Patients in the symbiotic group received one symbiotic tablet daily for 8 weeks whereas the placebo group received 1 placebo tablet. The hs-CRP concentration, TNF- $\alpha$ and IL-6 were measured by using ELISA kits. The dietary intakes of patients were assessed at the first and the end of the study and analyzed by Nutritionist IV. Data were analyzed by using SPSS 16.0 via paired and independent t- test.

Results: Anthropometric and dietary data were not significantly different between the two groups at the first and the end of the study. The serum concentrations of hs-CRP, IL- 6 and TNF- $\alpha$ decreased significantly in the symbiotic group at the end of week 8 compared to baseline $(p<0.05)$. Also, no significant changes were seen in the placebo group $(\mathrm{p}>0.05)$. The reduction in inflammatory markers in the symbiotic group were significant in compared to the placebo group $(\mathrm{P}<0.05)$.
\end{abstract}

Conclusions: Symbiotic supplementation can reduce serum hs-CRP, IL-6 and TNF- $\alpha$ concentrations, a risk factor for cardiovascular diseases.

Keywords: symbiotic, inflammation, type 2 diabetes mellitus

\section{Introduction}

Diabetes mellitus type 2 is an impendent risk factor for morbidity and mortality of cardiovascular diseases. Relative risk of cardiovascular disease is 2-3 times high in diabetic men and 3-4 times in diabetic women comparison to non-diabetic controls (Barrett et al., 1991; Steven et al., 1998; William et al., 1979). Risk factors for cardiovascular diseases such as lipid abnormalities and hypertensions are prevalent in diabetic patients but they cannot explain the high frequency of cardiovascular disease in these patients (Stenvinkel et al., 2004). Some studies have indicated that high concentrations of serum inflammation markers are an important risk factor for cardiovascular disease in type's diabetes patients (Reaven et al., 1988; Defronzo et al., 1991; Despres et al., 1996). Few reports are available on the correlation between hs-C-reactive protein (hs-CRP) and cardiovascular disease in type 2 diabetes patnts (Japer et al., 1999; Stehouwer et al., 2002). Also, tumor necrosis factor- $\alpha$ (TNF- $\alpha$ ) is an inflammatory cytokine that can alter in sensitivity in different ways by attenuating insulin receptor Signaling pathways, by decreasing glucose transporter -4 in adiposities and by suppressing adiponectin (Calle et al., 2012). Also, TNF- $\alpha$ increases the expression of genes encoding IL- 6 and Mcp-1 and contributes to the progression of atherosclerosis (Calle et al., 2012).

Interleukin- 6 (IL-6) is inflammatory markers that the main its effects is the induction of hepatic CRP production which to be an independent, major risk factor for cardiovascular disease (Ridker et al., 2003). Recent studies have proposed that IL- 6 could be involved in insulin resistance and diabetes and its complications (Bastard et al., 2006; Ray et al., 2009). 
Some studies were done to find treatment ways for lowing inflammation in diabetes patients (Alokail et al., 2013). Although, limited studies have been done on the effects of probiotic and synbiotic supplementation on serum systemic inflammation markers such as CRP, IL-6 and TNF- $\alpha$ in patients with type 2 diabetes (Kootte et al., 2012; Musso et al., 2011).The finding of these studies have been contradictory.

\section{Methods}

\subsection{Data Source and Study Population}

This study was a randomized double-blind, placebo- controlled trial. Forty-four type 2 diabetic patients (16 men and 28 women) were recruited from diabetic patients of diabetes clinic of Vaseei Hospital in Sabzevar, Iran. Type 2 diabetes was diagnosed according to the criteria of world health organization (World Health organization., 1985). The patients in this study did not have inflammatory and infectious diseases including hepatitis, and none of them received probiotic and prebiotic and omega- 3 fatty acids and L-carnitine supplement and steroidal and non-steroidal anti-inflammatory drugs. Participating were received metformin, glybenglamide and insuline for controlling blood sugar. During this study, the diabetic patients, type and dose of drugs did not altered for any of the patients.

Patients were randomized to symbiotic (pre and probiotic) or placebo group subjects in the symbiotic group received one symbiotic tablet daily for 8 weeks and the placebo group received 1 placebo tablet .

Patients were advised no change in their dietary habits, physical activities and drug regiments. At the first and the end of study, $5 \mathrm{ml}$ blood was collected from each patient after a 12- to 14-h fast. Blood samples after clotting at room temperature $\left(20-25^{\circ} \mathrm{C}\right)$ were centrifuged at $2000 \mathrm{rpm}$ for $10 \mathrm{~min}$. The sera were separated into small aliquots and frozen at $-70^{\circ} \mathrm{C}$ until they were used.

The serum hs-CRP concentration was determined by using enzyme-like immune-sorbent assay (ELISA) kits (Monobind, Inc., Lake Forest, Calif., USA). The CV for serum CRP was 2.9\%. Serum TNF- $\alpha$ and IL-6 were measured by using ELISA kits (Diaclone, Beancon, France). The CVs for serum TNF- $\alpha$ and IL-6 were $5.6 \%$ and $5.1 \%$ respectively.

Patients were weighted and heighted at baseline and at the end of week 8. In addition, the dietary intakes of patients were assessed using a 2-day food recall at the first and at the end of study. Subject's diets were analyzed by Nutritionist IV software (N squared computing, san Bruno, Calif., USA).

To ascertainment of subjects' compliance, we provided each patient with a fixed number of tablets and instructions to return the unconsumed tablets at the end of the study. The compliance rate for each patient was determined according to the number of returned tablets. The compliance of all subjects was more than $90 \%$ and no adverse events were reported.

\subsection{Statistical Analysis}

Statistical analysis of the data was performed by using statistical package for the social sciences (SPSS, Inc., Chicago, III., USA) for windows version 15. As all quantitative parameters were normally distributed according to the Kolmogorov-Smirnov test, we used the t-test and the paired t-test to compare parameters between and within groups, respectively. The differences were considered significant at $\mathrm{P}<0.05$.

\subsection{Ethnics}

The study protocol was approved by the Ethics committee of Sabzevar University of Medical Sciences. This study was in adherence with the Declaration of Helsinki Written informed consent which was obtained from all patients.

\section{Results}

The patients' baseline characteristics did not differ significantly between the two groups (Table 1). 
Table 1. Baseline characteristics and anthropometric data of diabetic patients in the symbiotic and placebo groups

\begin{tabular}{lll}
\hline Characterisfics & Symbiotic(n=22) & Placebo(n=22) \\
\hline Age (years) & $53.45 \pm 10.8$ & $54.5 \pm 11.10$ \\
\hline Duration (months) & $7.25 \pm 5.2$ & $7.45 \pm 5.4$ \\
\hline Sex & & \\
Men, $\mathbf{n}$ & $8(36.36 \%)$ & $8(36.36 \%)$ \\
Women, $\mathbf{n}$ & $14(63.63 \%)$ & $14(63.63 \%)$ \\
\hline Smoker, $\mathbf{n}$ & 0 & 0 \\
\hline BMI, $\mathbf{K g} / \mathbf{m}^{2}$ & $22.79 \pm 2.7$ & $22.47 \pm 2.38$ \\
\hline
\end{tabular}

Anthropometric and dietary data were not statistically different between the two groups at the baseline and the end of the study. In addition, these factors did not significantly change within each group during the study.

The serum concentrations of hs-CRP, IL- 6 and TNF- $\alpha$ decreased significantly in the symbiotic group at the end of the study compared to the first study $(\mathrm{p}<0.05)$. Also, no significant changes were observed in the placebo group ( $p>0.05$ ). The reduction in serum concentrations of hs-CRP, IL-6 and TNF- $\alpha$ in the symbiotic group were significant in compared to the placebo group $(\mathrm{P}<0.05$, Table 2$)$.

Table 2. serum concentrations of hs-CRP, IL- 6 and TNF- $\alpha$ in the symbiotic and placebo groups $(\mathrm{n}=22$ for all values)

\begin{tabular}{llll}
\hline Serum parameter and groups & Baseline & Week8 & P-value \\
\hline hs-CRP, mg/L & & & \\
\hline Synbiotic & $4.94 \pm 2.36$ & $4.15 \pm 1.96$ & 0.0001 \\
\hline Placebo & $5.00 \pm 2.31$ & $5.08 \pm 2.27$ & 0.412 \\
\hline IL- 6, ng/L & & & \\
Synbiotic & $9.19 \pm 5.97$ & $8.12 \pm 5.02$ & 0.011 \\
\hline Placebo & $8.89 \pm 5.18$ & $8.86 \pm 5.03$ & 0.489 \\
\hline TNF- $\boldsymbol{\alpha}, \mathbf{n g} / \mathbf{L}$ & & & \\
\hline Sybiotic & $8.03 \pm 2.73$ & $7.36 \pm 2.61$ & 0.002 \\
\hline Placebo & $8.64 \pm 2.61$ & $8.65 \pm 2.57$ & 0.956 \\
\hline
\end{tabular}

\section{Discussion}

Systemic inflammation is a common in the diabetes patients (Despres et al., 1996). It may lead to various complications including the cardiovascular disease in diabetes patients. Also, no treatment strategy for reducing inflammation in diabetes patients has been established yet (Calle et al., 2012).

In the present study, symbiotic supplementation significantly decreased serum hs-CRP, IL- 6 and TNF- $\alpha$. There is disagreement on the effect of synbiotic on serum systematic inflammation marker in diabetic patients.

Evidence is available on the anti inflammatory properties of probiotics. Some researches showed beneficial of probiotic using in diabetes type 2 but (Alokail et al., 2013) others reported no effect (Diamant et al., 2011; Esteve et al., 2011). Hatakka etal showed that Lactobacillus rhamnosus GG increased serum IL-1B and no effect on IL-6 and TNF- $\alpha$ and IL-10 (Hatakka et al., 2003).

In contrast, Marschan and et al showed that infants receiving probiotic had higher plasma levels of CRP and IL-10 comparison to group placebo (Marschan et al., 2008).

Asemi et al, showed that daily administration of multispecies probiotic supplements decreased in serum hs-CRP in diabetes patient in 8 weeks but in their study, effects of probiotc supplements was not evaluated on serum IL-6 and TNF- $\alpha$ (Asemi et al.,2013). 
CRP and IL-6, the two most sensitive markers of inflammation have been elevated in patients with type 2 diabetes (Pickup et al., 1997).

Also, high CRP level is reported to be a risk factor for progression type 2 diabetes (Voulgari et al., 2006).

Mazloom and et al indicated that administration of $1500 \mathrm{mg}$ probiotic capsules twice daily to 20 patients with type2 diabets for 6 weeks reduced serum IL-6 and elevated serum hs-CRP levels although not statistically significant(Mazloom et al.,2013).

\section{Conclusion}

In conclusion, symbiotic supplementation can reduce serum hs-CRP, IL-6 and TNF- $\alpha$ concentrations, a risk factor for cardiovascular diseases.

\section{Acknowledgements}

This study was supported by Sabzevar University of Medical Sciences of Sabzevar of Iran. The authors thank the staff and of diabetic clinic for valuable assistance the authors also grate fully acknowledge the cooperation of the participating patients.

\section{Disclosure}

The authors affirm that they have no conflict of interest to declare.

\section{References}

Alokail, M., Sabico, Sh., Al-Saleh, Y., Al-Daghri, N. M., Alkharfy, Kh. M., Vanhoutte, P. M., and et al. (2013). Effects of probiotics in patients with diabetes mellitus type2: study protocol for a randomized double-blind, placebo-controlled trial. Trails, 14, 195-203. http://dx.doi.org/10.1186/1745-6215-14-195

Asemi, Z., Zare, Z., Shakeri, H., Sabihi, S. S., \& Esmaillzadeh, A. (2013). Effect of Multispecies probiotic supplements on metabolic profiles, hs-CRP and oxidative stress in patients with type 2 Diabetes. Ann Nutr Metab, 63(1-2), 1-9. http://dx.doi.org/10.1159/000349922

Barrett-Connor, E. L., Cohn, B. A., Wingard, D. L., Edelstein, S. L. (1991). Why is diabetemellitus a stronger risk factor for fatal ischemic heart disease in womenthan in men? The Rancho Bernardo Study. JAMA, 265, 627-631. http://dx.doi.org/10.1001/jama.1991.03460050081025

Bastard, J. P., Maachi, M., Lagathu, C., Kim, M. J., Caron, M., Vidal, H., et al. Recent advances in relationship between obesity, inflammation and insulin resistance. Eur cytokine Netw, 17(1), 4-12. PMID PubMed: 16613757.

Calle, M. C., \& Fernandez, M. L. (2012). Inflammation and type 2 diabetes. Diabetes Metabolism, 38, 183-191. http://dx.doi.org/10.1016/j.diabet.2011.11.006

Defronzo, R. A., \& Ferannini, E. (1991). Insulin resistance: a multifaceted syndrome responsible for NIDDM, obesity, hyper tension, dyslipidemia and atherosclerotic cardiovascular disease. Diabetes care, 14, 173-194. PMID PubMed: 2044434. http://dx.doi.org/10.2337/diacare.14.3.173

Despres, J. P., Lamarch, B., Mauriege, P., Cantin, B., Dagenais, G., Moorgani, S., et al. (1996). Hyperinsulinemia as an independent risk factor for ischemic heart disease. $N$ Engl $J$ Med, 334, 952-958. http://dx.doi.org/10.1056/NEJM199604113341504

Diamant, M., Blaak, E. E., de Vos, W. M. (2011). Do nutrient-gut-microbiota interactions play a role in human obesity, insulin resistance and type 2 diabetes?. Obes Rev, 12, 272-281. http://dx.doi.org/10.1111/j.1467-789X.2010.00797.x.

Esteve, E., Ricart, W., \& Fernandez- Real, J. M. (2011). Gut microbiota interactions with obesity, insulin resistance and type 2 diabetes: did gut microbiota coevolve with insulin resistance?. Curr Opin Clin Nutr Metab Care, 14, 483-490. http://dx.doi.org/10.1097/MCO.0b013e328348c06d

Hatakka, K., Martio, J., Korpela, M., Herranen, M., Poussa, T., Laasanen, T., et al. (2003). Effects of probiotic therapy on the activity and activation of mild rheumatoid arthritis-a pilot study. Scand J Rheumatol, 32(4), 211-215. PMID PubMed: 14626627. http://dx.doi.org/10.1080/03009740310003695

Japer, A., Hinsvergh, V. W. M., kostense, P. J., Emeis, J. J., Yudkin, J. S., Nijpels, G., et al. Von Willebr and factor, C-reactive protein and 5-year mortality in diabetic and non-diabetic subjects. The Hoorn study Arterioscl Tromb Vasc Biol, 19, 3071-3078. http://dx.doi.org/10.1161/01.ATV.19.12.3071

Kootte, R. S., Vrieze, A., Holleman, F., Dallinga-Thie, G. M., Zoetenda, E. G., de Vos, W. M, et al. (2012). The 
therapeutic potential of manipulationg gut microbiota in obesity and type 2 diabetes mellitus. Diabetes Obes Metab, 14, 112-120. http://dx.doi.org/10.1111/j.1463-1326.2011.01483.x

Marschan, E., Kuitunen, M., Kukkonen, k., Poussa, T., Sarnesto, A., Haahtela, T., et al. (2008). Probiotics in infancy induce protective immune profiles that are characteristic for chronic low grade inflammation. Clin EXP Allergy, 38, 611-618. http://dx.doi.org/10.1111/j.1365-2222.2008.02942.x

Mazloom, Z., Yousefinegad, A., \& Dabbaghmanesh, M. H. (2013). Effect of probiotics on lipid profile, glycemic control, insulin action, oxidative stress and inflammatory markers in patients with type 2 diabetes: A clinical trail. IJMS, 38(1): 38-43.

Musso, G., Gambino, R., \& Cassader, M. (2011). Interactions between gut and host metabolism predisposing to obesity and diabetes. Ann Rev Med, 62, 361-380. http://dx.doi.org/10.1146/annurev-med-012510-175505

Pickup, J. C., Mattock, M. B., Chusney, G. D., \& Burt, D. (1997). NIDDM as a disease of the innate immune system: association of acute-phase reactants and interleukin-6 with metabolic syndrome X. Diabetologia, 40, 1286-1292. PMID PubMed: 9389420. http://dx.doi.org/10.1007/s001250050822

Ray, A., Huisman, M. V., \& Tamsma, J. T. The role of inflammation on atherosclerosis, intermediate and clinical cardiovascular endpoint in type 2 diabetes mellitus. Eur $J$ Internal Med, 20(3), 253-260. http://dx.doi.org/10.1016/j.ejim.2008.07.008

Reaven, G. M. (1988). Role of insulin resistance in human disease. Diabetes, 37, 1595-1607. http://dx.doi.org/10.1016/S0899-9007(97)80637-5

Ridker, P. M. (2003). Clinical application of c-reactive protein for cardiovascular disease detection and prevention. Circulation, 107, 363-369. http://dx.doi.org/10.1161/01.CIR.0000053730.47739.3C

Stehouwer, C. D. A., Gall, M., Twisk, J. W. R., Knudsen, E., Emeis, J. J., \& Parving, H. (2002). Increased urinary albumin excretion, endothelial dysfunction and chronic low-grade inflammation in type 2 diabetes. Diabetes, 51, 1157-1165. http://dx.doi.org/10.2337/diabetes.51.4.1157

Stenvinkel, P., \& Yeun, Jy. (2004). Role of inflammation in malnutrition and atherosclerosis in chronic renal failure. In J. D. kopple, \& S. G. Massry (eds.), kopple Massry's nutritional management of renal disease (pp. 199-212). Philadelphia, Lippicott, Williams Wilkins.

Steven, M., Haffner, M. D., Seppo Lehto, M. D., Tapani Rönnemaa, M. D., Kalevi Pyörälä, M. D., \& Markku Laakso, M. D. (1998). Mortality from Coronary Heart Disease in Subjects with Type 2 Diabetes and in Nondiabetic Subjects with and without Prior Myocardial Infarction. $N$ Engl J Med, 339, 229-234. http://dx.doi.org/10.1056/NEJM199807233390404

Voulgari, Ch., Tentolouris, N., Moyssakis, I., Dilaveris, P., Gialafos, E., Papadogiannis, D., et al. (2006). Spatial QRS-T angle: association with diabetes and left ventricular performance. Eur J Clin Invest, 36, 608-613. http://dx.doi.org/10.1111/j.1365-2362.2006.01697.x

William, B., Kannel, M. D., Daniel, L. (1979). Diabetes and cardiovascular disease. The Framingham study. JAMA , 241, 2035-2038. http://dx.doi.org/10.1001/jama.1979.03290450033020

World Health organization. (1985). Diabetes mellitus. Report of WHO study group. Geneva; 1985. (Tech. Rep. Ser., No. 727).

\section{Copyrights}

Copyright for this article is retained by the author(s), with first publication rights granted to the journal.

This is an open-access article distributed under the terms and conditions of the Creative Commons Attribution license (http://creativecommons.org/licenses/by/3.0/). 